\title{
Neck posture and overall body design in sauropods
}

\author{
Andreas Christian ${ }^{1}$ \\ With 11 figures and 5 tables
}

\begin{abstract}
The stress on the intervertebral discs in the necks of Brachiosaurus brancai, Diplodocus carnegii, and Dicraeosaurus hansemanni are calculated for various hypothetical neck postures. Assuming similar safety factors along the neck and a predominance of static or quasistatic forces, neck postures in which the stress is not more or less constant along the neck are rejected. The necks of two large and long-necked recent mammals, Giraffa camelopardalis and Camelus sp., are examined in the same way in order to test the method. The method is shown to be suitable for the reconstruction of the habitual posture of longnecked terrestrial vertebrates, even if the distribution of mass along the head and neck and the lever arms of the neck muscles and ligaments are only roughly estimated. Among sauropods, the neck posture differed considerably, being nearly vertical in Brachiosaurus brancai, but more horizontal in Dicraeosaurus hansemanni and especially in Diplodocus carnegii. Therefore, Brachiosaurus brancai appears to have been an extremely specialised high browser, whereas in Diplodocus carnegii and in Dicraeosaurus hansemanni the long neck permitted a large feeding volume. The contrast in neck posture is reflected in the overall body design, especially in tail and limb length.
\end{abstract}

Key words: dinosaurs, sauropods, neck posture, biomechanics, functional morphology, feeding, ecology.

\section{Zusammenfassung}

Für verschiedene Halsstellungen von Brachiosaurus brancai, Diplodocus carnegii und Dicraeosaurus hansemanni wurde der Druck auf den Gelenkknorpel der Zwischenwirbelgelenke berechnet. Halsstellungen, die nicht zu einem mehr oder weniger konstanten Druck entlang des Halses führten, wurden verworfen. Dabei wurden gleiche Sicherheitsfaktoren des Gelenkknorpels sowie das Vorherrschen von statischen und quasistatischen Kräften entlang des Halses angenommen. Die Hälse zweier langhalsiger Säugetiere, Giraffa camelopardalis und Camelus sp., wurden in gleicher Weise analysiert, um die Methode zu überprüfen. Diese erwies sich als geeignet, die habituelle Halsstellung eines langhalsigen terrestrischen Wirbeltieres zu rekonstruieren, selbst wenn die Massenverteilung entlang des Halses und die Hebelarme der epaxialen Muskeln, Sehnen und Bänder nur grob geschätzt werden können. Unter den Sauropoden variiette die Halsstellung erheblich von nahezu vertikal bei Brachiosaurus brancai bis zu eher horizontal bei Diplodocus carnegii. Die Halsstellung von Dicraeosaurus hansemanni lag näher bei der Halsstellung von Diplodocus als von Brachiosaurus. Offenbar war Brachiosaurus darauf spezialisiert, Nahrung aus großen Höhen aufzunehmen, während Diplodocus und Dicraeosaurus ihre langen Hälse zum Abweiden eines weiten Areals nutzten. Die Unterschiede in der Halsstellung spiegeln sich in der Körperform, insbesondere in der Schwanz- und Beinlänge, wider.

Schlüsselwörter: Dinosaurier, Sauropoden, Halsstellung, Biomechanik, Funktionelle Morphologie, Nahrungsaufnahme, Ökologie.

\section{Introduction}

All sauropod dinosaurs are characterised by a long neck, a long tail, a rather bulky trunk, four pillar-like limbs and a high body weight (e.g., McIntosh 1990). However, a closer look reveals distinct differences in body shape among sauropods. Whereas the necks of cetiosaurids and camarasaurids are comparatively short, the necks of some diplodocids such as Diplodocus or Barosaurus reach extreme length (e.g., Bonaparte 1986, McIntosh 1990). In Brachiosaurus as well as in Diplodocus, the neck comprises about 2/3 of the presacral vertebral column. Compared to other diplodocids the neck of Dicraeosaurus is short, comprising just about one half the presacral vertebral column. There is much variation in tail length among sauropods. In Brachiosaurus

\footnotetext{
1 Universität Flensburg, Institut für Biologie und Sachunterricht und ihre Didaktik, Mürwiker Str. 77, D-24943 Flensburg, Germany.

Received March, accepted June 2002
} 
the tail is shorter than the neck. By contrast, the tail is approximately twice as long as the neck in Diplodocus and even longer compared to the neck in Dicraeosaurus. In most sauropods, the forelimbs are shorter than the hindlimbs, whereas in Diplodocus and Dicraeosaurus, forelimb length is about $2 / 3$ of hindlimb length. By contrast, in Brachiosaurus the forelimbs are longer than the hindlimbs. It seems reasonable to assume that these differences in the overall body design among sauropods reflect ecological differences, especially in the feeding strategy.

Neck posture is a crucial feature in the mechanics, the ecology and the physiology of a sauropod. Yet, neck posture in sauropods is still the subject of much controversy. The cervical vertebrae can be arranged in different, yet apparently reasonable ways, although these result in considerable differences in neck posture. Models based on proper articulation of adjacent vertebrae, however, can be useful in limiting possible neck postures in well preserved sauropods (Stevens \& Parrish 1999). Most workers seem to favour low or medium height neck postures in Diplodocus and its close relatives (e.g., McIntosh 1990, or Fastovsky \& Weishampel 1996 for summarises, Stevens \& Parrish 1999). However, more vertical postures are preferred by others (Bakker 1987, Paul 1987). Moreover, the vertical neck posture might have been adopted during a tripodal stance, with the tail used as the third prop (Bakker 1987, Paul 1987).

In Brachiosaurus, proposed neck postures differ from very low to nearly vertical. Frey \& Martin (1997) assumed a practically horizontal posture for the neck, while in many reconstructions of Brachiosaurus, the neck is inclined forward at an angle of about $30^{\circ}$ to the vertical (Janensch 1950), similar to the neck posture often observed in giraffes. Some workers favour the idea of a rather upright ("vertical"), more or less S-shaped neck posture (Bakker 1987, Paul 1988, Christian \& Heinrich 1998). The possible range of neck movements has also been widely discussed. According to Christian \& Heinrich (1998), for example, neck movements in Brachiosaurus were rather limited, whereas Gunga \& Kirsch (2001) conclude from studies of the inner ear of this sauropod that the neck posture varied from a vertical to a more horizontal posture during feeding.

The posture of the neck reflects its utilisation. The neck of a sauropod might have been used primarily for browsing high above the ground as in a giraffe (Bakker 1987, Paul 1988) or, in a different model, a long neck could have pro- vided a large volume of feeding space by sweeping both laterally and vertically (Martin 1987). While the first proposal seems reasonable especially in forms like Brachiosaurus that have long forelimbs, the second proposal seems more suitable for forms such as Diplodocus that have short forelimbs and apparently more flexible necks.

A very long neck, however, causes physical problems that might lead to constraints in its use. The dorsal neck muscles of Diplodocus carnegii were hardly able to lift the neck from a horizontal to a vertical position, as shown by Alexander (1985). Lifting the neck seems likely to have been a strenuous activity for this dinosaur. Another serious problem concerns the blood pressure required to perfuse the brain of an animal with a highly elevated head (Hohnke 1973, Seymour 1976, Hargens et al. 1987, Pedley 1987, Dodson 1990, Badeer \& Hicks 1996, Seymour \& Lillywhite 2000). In order to avoid imposing dangerous stresses on the cardiovascular system, sauropods may have habitually fed at moderate levels, but browsing relatively high above the ground only for short periods (Dodson 1990). However, we cannot exclude the possibility of mechanisms that might have enabled sauropods to cope with physiological problems associated with a high elevation of the head. Such mechanisms have been described for giraffes (Dagg \& Foster 1976, Hargens et al. 1987, Pedley 1987).

Since different methods for reconstructing the neck posture of a sauropod lead to different results, it is necessary either to assess which methods are more reliable, or to develop new methods that are suitable for corroborating or falsifying different hypotheses. In this study a direct, robust and reliable, yet seldom utilised mechanical method is used to reconstruct the habitual neck posture of three different sauropods. The method is based on the fact that different postures of the neck, limbs, and body result in different patterns of stress in the skeleton of a vertebrate (e.g., Kummer 1959, Pauwels 1965, Preuschoft 1969, 1970, 1976, Alexander 1985, 1989, Christian \& Preuschoft 1996). If the skeletal remains of an extinct vertebrate are analysed with regard to the forces and torques that could have been sustained, we may be able to constrain the range of possible postures (and gaits) of this animal (e.g., Preuschoft 1976, Alexander 1985, 1989, Christian \& Preuschoft 1996). In the method used here, the postulated predominant neck posture of three sauropods is deduced from the shape of the vertebral column by applying the method developed by Preuschoft (1976) to 
Table 1

Camel: estimates of relative segment masses $(\mathrm{m})(100 \%=$ head + neck), cross-sectional areas (A) of the intervertebral joints, and calculated compressive force $(\mathbf{k} \cdot \mathbf{F})$ on the intervertebral discs (see text for calculation method) at different locations along the neck for the hypothetical neck postures (A-D) illustrated in Fig. 1. x: distance from the occipital condyle. k: constant factor.

\begin{tabular}{lrrllll}
\hline $\mathrm{x}[\mathrm{m}]$ & $\mathrm{m}[\%]$ & $\mathrm{A}\left[\mathrm{m}^{-4}\right]$ & $\mathrm{k} \cdot \mathrm{F}_{\mathrm{A}}[\mathrm{N}]$ & $\mathrm{k} \cdot \mathrm{F}_{\mathrm{B}}[\mathrm{N}]$ & $\mathrm{k} \cdot \mathrm{F}_{\mathrm{C}}[\mathrm{N}]$ & $\mathrm{k} \cdot \mathrm{F}_{\mathrm{D}}[\mathrm{N}]$ \\
\hline 0,00 (head) & 40,0 & & & & & \\
0,205 & 12,9 & 8,95 & 193,3 & 307,4 & 295,9 & 193,3 \\
0,335 & 7,7 & 11,66 & 238,4 & 553,3 & 486,2 & 236,3 \\
0,465 & 9,0 & 14,24 & 220,5 & 629,4 & 538,5 & 290,9 \\
0,590 & 10,1 & 16,10 & 189,3 & 584,8 & 502,0 & 306,9 \\
0,705 & 10,8 & 16,89 & 183,5 & 610,2 & 522,7 & 333,4 \\
0,790 & 9,4 & 13,21 & 172,6 & 552,3 & 482,5 & 290,0
\end{tabular}

Table 2

Giraffe: estimates of relative segment masses $(\mathrm{m})(100 \%=$ head+neck $)$, cross-sectional areas (A) of the intervertebral joints, and calculated compressive force $(\mathrm{k} \cdot \mathrm{F})$ on the intervertebral discs (see text for calculation method) at different locations along the neck of two individuals ( $\mathbf{2 A}$ and $\mathbf{2 B}$ ) for the hypothetical neck postures (A-D) illustrated in Fig. 3. $x$ : distance from the occipital condyle. $\mathrm{r}$, s: constant factors.

Table 2A

\begin{tabular}{lllllll}
\hline $\mathbf{x}[\mathrm{m}]$ & $\mathrm{m}[\%]$ & $\mathbf{A}\left[\mathrm{m}^{-4}\right]$ & $\mathbf{r} \cdot \mathrm{F}_{\mathrm{A}}[\mathrm{N}]$ & $\mathbf{r} \cdot \mathrm{F}_{\mathrm{B}}[\mathrm{N}]$ & $\mathbf{r} \cdot \mathrm{F}_{\mathrm{C}}[\mathrm{N}]$ & $\mathrm{r} \cdot \mathrm{F}_{\mathrm{D}}[\mathrm{N}]$ \\
\hline 0,00 (head) & 33,9 & & & & & \\
0,32 & 7,4 & 19,23 & 265,4 & 263,1 & 215,6 & 135,5 \\
0,56 & 7,2 & 21,17 & 369,1 & 355,2 & 268,9 & 133,3 \\
0,78 & 8,1 & 29,70 & 464,5 & 440,9 & 319,8 & 133,6 \\
1,00 & 9,5 & 30,35 & 596,4 & 559,4 & 392,3 & 139,8 \\
1,22 & 12,6 & 34,75 & 731,4 & 682,2 & 469,2 & 149,3 \\
1,40 & 20,3 & 35,06 & 688,1 & 653,0 & 457,1 & 153,0
\end{tabular}

Table 2B

\begin{tabular}{lllllll}
\hline $\mathbf{x}[\mathrm{m}]$ & $\mathrm{m}[\%]$ & $\mathrm{A}\left[\mathrm{m}^{-4}\right]$ & $\mathrm{s} \cdot \mathrm{F}_{\mathrm{A}}[\mathrm{N}]$ & $\mathrm{s} \cdot \mathrm{F}_{\mathbf{B}}[\mathrm{N}]$ & $\mathrm{s} \cdot \mathrm{F}_{\mathrm{C}}[\mathrm{N}]$ & $\mathrm{s} \cdot \mathrm{F}_{\mathrm{D}}[\mathrm{N}]$ \\
\hline 0,00 (head) & 33,9 & & & & & \\
0,41 & 7,4 & 25,05 & 199,1 & 202,5 & 170,6 & 111,9 \\
0,70 & 7,2 & 31,23 & 295,3 & 289,0 & 223,5 & 116,3 \\
0,97 & 8,1 & 31,67 & 365,0 & 352,5 & 261,8 & 117,1 \\
1,255 & 9,5 & 39,93 & 457,3 & 436,6 & 314,1 & 122,6 \\
1,52 & 12,6 & 47,69 & 531,9 & 506,9 & 359,8 & 130,1 \\
1,78 & 20,3 & 49,07 & 458,8 & 452,0 & 333,6 & 135,3
\end{tabular}

deduce the patterns of bending moments and compressive forces in the vertebral column along the longitudinal body axis. This method will be referred to as the Preuschoft method. A similar method has been used by Alexander (1985). Among a variety of extinct and extant vertebrate species, the Preuschoft method has been shown to yield reliable results for body posture, even if the necessary data on segment masses, lever arms and surface areas are biased by high systematic errors (Christian \& Preuschoft 1996), as will be discussed below.

\section{Materials and Method}

\section{Materials}

The analysis of Brachiosaurus brancai is based on data presented by Christian \& Heinrich (1998). Measurements for skeletal features of Diplodocus carnegii and Dicraeosaurus hansemanni were obtained from the cast of the holotype of Diplodocus carnegii and the mounted skeleton of Dicraeosaurus hansemanni in the Museum für Naturkunde der Humboldt-Universität zu Berlin, Germany. Giraffes and camels were studied in the Allwetterzoo Münster, Germany, and in the Zoo Dortmund, Germany, as well as from videos of individuals in the wild. Measurements on the neck skeleton were obtained from the skeleton of a male adult giraffe (Giraffa camelopardalis) in the Museum Alexander Koenig, Bonn, Germany (registration number 80.320), as well as from the skeletons of a male adult giraffe (Giraffa camelopardalis) and an adult camel (Camelus sp.) in the Museum für Naturkunde der Humboldt-Universität zu Berlin (no catalogue numbers).

\section{Method}

The neck, trunk, and tail of an animal experience forces and torques (bending moments) that are a function of the posture and the distribution of body mass. Bending moments along the longitudinal body axis act primarily in a sagittal plane unless rapid lateral accelerations take place. The pattern of bending moments along the vertebral column depends on mass distribution, posture, and the forces ex- 
changed between the animal and the substrate (ground reaction forces) (Christian \& Preuschoft 1996). In the neck, bending moments are usually highest at the base and decrease towards the head. In a vertical position, however, the neck experiences weak bending moments and weight forces are predominant.

Bending moments, $M$, along the neck can be calculated according to the rules of statics (e.g., Pauwels 1965). In this study, the calculations of bending moments along sauropod necks are based on the mass distributions determined by Gunga et al. (1995, 1999). These data allow calculation of the bending moments and the weight forces at different locations along the neck, but the locations do not match the positions of the joints between the vertebral centra. The bending moments and weight forces at the locations of the intervertebral joints were estimated by linear interpolation. The segment masses estimated by Gunga et al. $(1995,1999)$ appear, in general, to be too high because circular instead of elliptical cross-sectional areas were assumed. However, a systematic error in segment mass estimates does not affect the results of the Preuschoft method because only relative segment masses are of importance. Only marked relative differences between the masses of different neck segments would considerably affect the calculated pattern of forces along the neck. Therefore, the same results would have been obtained with an overall lighter (or heavier) neck and head. In Brachiosaurus and Diplodocus, the reliability of the data for segment mass was successfully tested by using plastic scale models in order to estimate segment masses. The neck of the models was cut into pieces at the positions of the intervertebral joints. Relative segment weights were obtained by weighting these pieces. The results were in fair accordance with the estimates of relative segment masses based on the data of Gunga et al $(1995,1999)$ as described above. The plastic models, however, tend to have heads that are too large. On the other hand, especially in Brachiosaurus, the volume of the basal region of the neck may have been overestimated as modelled by Gunga et al. $(1995,1999)$ who modelled a very smooth transition between the neck and trunk.

In the mammals studied, the mass distribution along the neck and head was estimated from plastic scale models as well as from measurements taken from live animals. Segment masses were assumed to be equal to segment volumes. In the head, $20 \%$ (camel) or $30 \%$ (giraffe) were added because of the greater amount of bone (estimated values based on skull weight).

As long as the neck is not orientated backwards, bending moments along the neck must be counteracted at the intervertebral junctions by tension in epaxial muscles, tendons, or ligaments that are located dorsal to the vertebral centra (Preuschoft 1976, Alexander 1985, 1989, Christian \& Preuschoft 1996, Christian \& Heinrich 1998). A muscle, tendon, or ligament force $F_{m}$ acting in a sagittal plane above the transverse axis of an intervertebral joint produces a torque $F_{m} \cdot h$ about that joint, where $h$ is the lever arm of the force $F_{m}$. The lever arm is the distance between the line of action of the force and the axis of the joint. The transverse axis of an intervertebral joint can be assumed to pass through the centre of the intervertebral disc (Preuschoft 1976, Alexander 1985). The lever arms of the epaxial muscles can be estimated to be equal to the vertical distances between the centres of the intervertebral discs and either the centres of the epaxial muscles (Preuschoft 1976), or the line that connects the tips of the neural spines (Alexander 1985). Both methods lead to different absolute values, but to similar results if only the general pattern of torques along the vertebral column is of interest (Christian \& Preuschoft 1996). In any case, as long as the general construction of the vertebrae of the individual under study is similar along the neck, the mean lever arm of all muscles, tendons, and ligaments effective at a given joint between two vertebral centra is a constant fraction of the distance between the centre of the intervertebral disc and the line connecting the tips of the neural spines. In this study, the lever arm $h$ is estimated as the distance between the centre of an intervertebral disc and the line connecting the tips of the neural spines.

Difficulties in estimating $h$ arise if epaxial muscles, tendons, or ligaments are located far above the spinal processes in certain parts of the neck. This is quite common in the necks of mammals (Preuschoft \& Fritz 1977, Preuschoft \& Günther 1994), but unlikely in most regions of the sauropod neck with the possible exception of the basal neck region (see below, see also Paul 1988, Christian \& Heinrich 1998) because neither the shape of the neural spines nor the rather moderate length of the neural spines in the shoulder region indicate the existence of muscles, tendons, or ligaments that were located considerably above the tips of the neural spines,

In order to test the reliability of the method applied here to sauropod skeletons, in the mammals studied, the lever arms (h) were determined in the same way as for the sauropods despite the problems mentioned above. However, in the long necks of giraffes and camels, it is less critical to estimate the lever-arms in this way than in shorter-necked mammals (e.g., horses), with ligaments that run high above the neural spines at the base of the neck, but are lower towards the head.

The pulling force, $F_{m}$, of the epaxial muscles produces a compressive force of the same magnitude between the vertebral centra (Preuschoft 1976, Alexander 1985, Christian \& Preuschoft 1996, Christian \& Heinrich 1998). This compressive force acts on the cartilage in the intervertebral joint, the intervertebral disc (it is of no importance here, whether the joints between two vertebral centra in the necks of sauropods were synarthroses or diathroses). The muscle force, $F_{m}$, at a given position in the vertebral column can be calculated by $F_{m}=$ constant $\cdot M / h$ (Preuschoft 1976 , Alexander 1985, Christian \& Preuschoft 1996). M is the bending moment in the sagittal plane at the position investigated. The total compressive force, $F$, acting on an intervertebral disc is the sum of two components: first, the muscle force, $F_{m}$, due to the bending moment, $M$, as described above, and second, the weight force, $F_{g}$, of the fraction of the neck cranial to the position investigated multiplied by the cosine of the angle $\varphi$ between the plane of the intervertebral joint and the horizontal plane (see Preuschoft 1976, Christian \& Preuschoft 1996, Christian \& Heinrich 1998). Thus:

$\mathrm{F}=\mathrm{F}_{\mathrm{m}}+\mathrm{F}_{\mathrm{g}} \cdot \cos \varphi$.

Forces different from static or quasistatic forces are neglected, assuming that forces due to accelerations or other activities are not predominant. This assumption seems reasonable for sauropods (but see below) and also for giraffes and camels, despite the occasional use of the head for combat in the mammals studied. Under the assumption of equal safety factors, the highest regularly occurring compressive forces, F, acting on the intervertebral discs along the neck should be proportional to the transverse cross-sections, A, of the intervertebral discs (Preuschoft 1976, Christian \& Preuschoft 1996, Christian \& Heinrich 1998). Consequently, the stress on the intervertebral discs, equivalent to the force $F$ divided by the cross-sectional area $A$ of the intervertebral discs, should be constant along the neck. For Diplodocus, Dicraeosaurus, and the mammals studied, the transversal crosssection, A, of each intervertebral disc was calculated by assuming an elliptical shape, with the transverse and dorsoventral diameters of the cranial surface of the adjacent vertebral centrum used as the major axes. At the base of the neck a projection of the areas of the zygapophyses onto the plane of the adjacent intervertebral disc was added, where necessary. The data for Brachiosaurus were obtained from Christian \& Heinrich (1998), who used the caudal surface of the vertebral centra for estimating the cross-sectional areas of the intervertebral discs. In the sauropod necks studied here, caudal and cranial surfaces of contiguous vertebral centra were ap- 
proximately proportional, so that two sources of measurements were available. In mammalian necks, however, the caudal surface of the vertebral centra can be much larger than the compressed area of cartilage. Therefore, measurements were taken from the cranial surface. The distances of the intervertebral joints from the occipital condyle were measured along the vertebral centra.

In all animals studied, various hypothetical neck postures were tested (Figs 1, 3, 6, 8, 10). The neck was divided into segments, each starting and ending at the position of an intervertebral disc. For all hypothetical neck postures, the compressive forces, $\mathrm{F}$, were calculated along the neck and divided by the cross-sectional areas, $A$, of the intervertebral joints. The stress, F/A, was expected to be more or less constant for habitual postures. For each hypothetical neck posture, the stress on the intervertebral discs along the neck was plotted in a diagram (Figs 2, 4, 5, 7, 9, 11). The hypothetical posture was rejected if the stress was not approximately constant along the neck. The stress patterns are conclusive without further statistical processing of the data. However, for each hypothetical neck posture, the ratio between the standard deviation (SD) of the stress values and the mean stress was calculated. In a habitual posture this ratio (SD/mean) should be considerably lower than in a neck posture that was not frequently adopted.

The use of relative values for forces or stresses along the whole neck, is a strength of the Preuschoft method because it is not affected by systematic errors in estimates of segment masses, lever arms, muscle forces or cross-sectional areas of intervertebral discs. By contrast, analyses that are based on absolute values of force or stress that are effective at certain positions of the neck are highly sensitive to such errors in the parameters mentioned above. Therefore, by using the Preuschoft method, it is of no importance whether reconstructions of the head and neck are too heavy, or too light, or whether estimates of lever arms or cross-sectional areas are too high or too low, as long as the errors are similar along the neck.

\section{Results}

Only relative values of force and stress are relevant in these analyses, as explained above. Therefore, absolute values were not calculated. Forces and stresses are given in arbitrary units (Newtons per square meter times a constant that is the same in each individual but may differ between individuals). Non-systematic errors for data on stress are about $15 \%$ in the dinosaurs

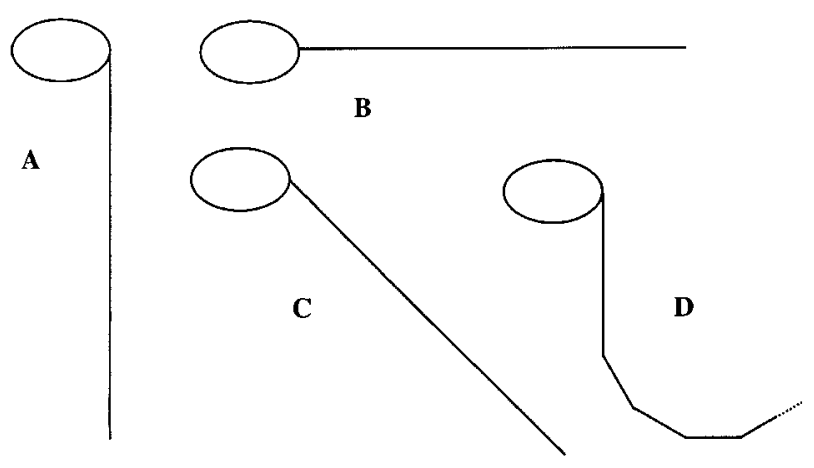

Fig. 1. Hypothetical neck postures in the camel. $\mathbf{A}$, vertical; $\mathbf{B}$, horizontal; $\mathbf{C}$, intermediate $\left(45^{\circ}\right.$ to the vertical $)$; $\mathbf{D}$, natural posture.

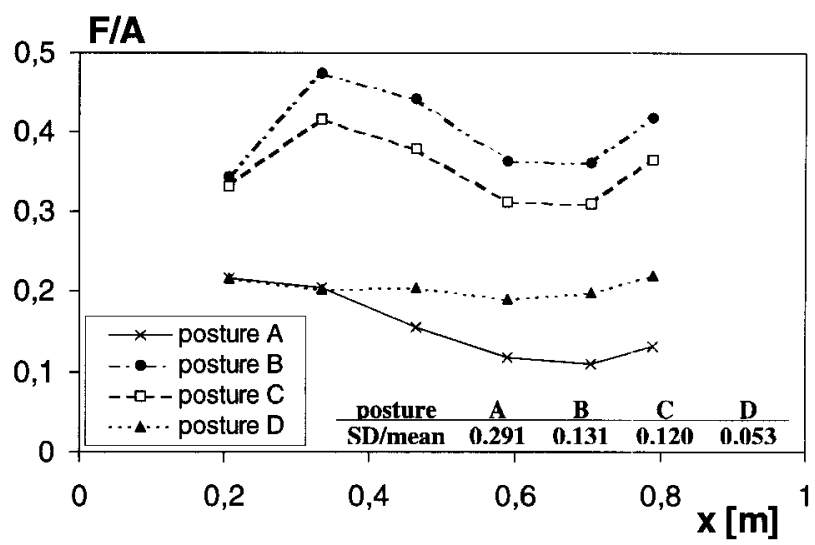

Fig. 2. Stress (F/A) on the intervertebral joints along the neck of the camel calculated for the hypothetical neck postures presented in Fig. 2. Stress is given in arbitrary units. $\mathrm{x}$ : distance from the occipital condyle. SD/mean: standard deviation of stress values divided by mean stress.

and $5-10 \%$ in the mammals and attributable to errors in the estimated cross-sectional areas (about $10 \%$ and $5 \%$, respectively) and lever arms (about $10 \%$ ).

The hypothetical neck postures analysed and the distributions of stress on the intervertebral discs along the neck are illustrated in Figures 1 to 11. Relevant data are presented in Tables 1 to 5 .

In the camel, stress on the intervertebral joints is approximately constant along the neck only in the habitual neck posture (Fig. 1D and Fig. 2), as expected. In this posture, the standard deviation of stress values is much lower compared to the mean stress $(\mathrm{SD} /$ mean $=0.053)$ than in the other postures tested (SD/mean between 0.120 and 0.291).

Giraffes show much greater variation in neck posture than camels. Generally, the neck is held in a forwardly inclined position, deviating about $30^{\circ}$ from the vertical (Fig. 3C). Lower or more upright positions of the neck occur less frequently, though such postures are not uncommon during feeding. As expected, stress values are nearly constant along the neck in the most commonly assumed posture (SD/mean between 0.08 and 0.09 ), but show greater differences in less frequently assumed neck postures $(\mathrm{SD} /$ mean between 0.122 and 0.199 in the first individual and between 0.137 and 0.228 in the second giraffe) (Figs 4, 5). Despite the much higher stresses on the intervertebral discs resulting from more horizontal neck positions, these postures do not determine the cross-sectional areas of the intervertebral discs, although such postures are not uncommon. If a posture that results in higher forces is frequently assumed, it should determine the shape of the neck, even if other, less strenu- 
Table 3

Brachiosaurus brancai: estimates of relative segment masses $(\mathrm{m})(100 \%=$ head + neck $)$, cross-sectional areas (A) of the intervertebral joints, and calculated compressive force $(k \cdot F)$ on the intervertebral discs (see text for calculation method) at different locations along the neck for the hypothetical neck postures (A, B) illustrated in Fig. 6 and for a horizontal posture (C). $\mathrm{x}$ : distance from the occipital condyle. c: constant factor.

\begin{tabular}{|c|c|c|c|c|c|}
\hline $\mathrm{x}[\mathrm{m}]$ & $\mathrm{m}[\%]$ & $A\left[m^{-4}\right]$ & $\mathrm{c} \cdot \mathrm{F}_{\mathrm{A}}[\mathrm{N}]$ & $c \cdot F_{B}[N]$ & $c \cdot F_{C}[N]$ \\
\hline 0,00 (head) & 1,280 & & & & \\
\hline 0,82 & 2,047 & 151 & 7,8 & 9,7 & 8,6 \\
\hline 1,42 & 2,084 & 250 & 13,6 & 13,9 & 14,8 \\
\hline 2,14 & 3,574 & 253 & 22,5 & 17,5 & 26,0 \\
\hline 2,98 & 5,566 & 341 & 38,2 & 23,1 & 52,4 \\
\hline 3,82 & 5,667 & 377 & 54,4 & 28,7 & 79,8 \\
\hline 4,76 & 7,833 & 471 & 77,8 & 36,5 & 110,2 \\
\hline 5,67 & 8,381 & 658 & 106,0 & 44,7 & 160,5 \\
\hline 6,55 & 10,173 & 660 & 146,0 & 68,9 & 219,9 \\
\hline 7,41 & 16,854 & 709 & 216,0 & 119,0 & 315,0 \\
\hline 8,20 & 36,541 & 939 & 293,0 & 256,0 & 409,8 \\
\hline
\end{tabular}

Table 4

Diplodocus carnegii: estimates of relative segment masses $(\mathrm{m})(100 \%=$ head + neck $)$, cross-sectional areas (A) of the intervertebral joints, and calculated compressive force $(k \cdot F)$ on the intervertebral discs (see text for calculation method) at different locations along the neck $(A-E)$ for the hypothetical neck postures illustrated in Fig. 8 . x: distance from the occipital condyle. d: constant factor.

\begin{tabular}{|c|c|c|c|c|c|c|c|}
\hline $\mathrm{x}[\mathrm{m}]$ & $\mathrm{m}[\%]$ & $A\left[m^{-4}\right]$ & $\mathrm{d} \cdot \mathrm{F}_{\mathrm{A}}[\mathrm{N}]$ & $\mathrm{d} \cdot \mathrm{F}_{\mathrm{B}}[\mathrm{N}]$ & $\mathrm{d} \cdot \mathrm{F}_{\mathrm{C}}[\mathrm{N}]$ & $d \cdot F_{D}[N]$ & $\mathrm{d} \cdot \mathbf{F}_{\mathrm{E}}[\mathrm{N}]$ \\
\hline 0,00 (head) & 4,226 & & & & & & \\
\hline 0,19 & 2,305 & 19,15 & 3929 & 4708 & 2322 & 4237 & 3929 \\
\hline 0,42 & 1,537 & 28,59 & 6016 & 6738 & 3342 & 6240 & 6987 \\
\hline 0,695 & 2,305 & 49,59 & 8276 & 8399 & 5264 & 8491 & 9002 \\
\hline 1,05 & 2,766 & 57,26 & 11627 & 9653 & 8172 & 11747 & 11871 \\
\hline 1,44 & 3,112 & 73,04 & 16117 & 9916 & 12119 & 16032 & 15608 \\
\hline 1,90 & 3,650 & 94,91 & 21071 & 10117 & 16455 & 20788 & 19769 \\
\hline 2,38 & 3,765 & 119,7 & 27550 & 10687 & 22215 & 26880 & 25031 \\
\hline 2,89 & 3,995 & 163,3 & 37367 & 11665 & 31092 & 35892 & 32694 \\
\hline 3,465 & 5,071 & 229,5 & 50723 & 12960 & 43199 & 48105 & 43053 \\
\hline 4,04 & 6,185 & 310,2 & 65872 & 14492 & 56894 & 62014 & 54882 \\
\hline 4,63 & 7,914 & 355,9 & 80904 & 16287 & 70328 & 76042 & 66940 \\
\hline 5,24 & 9,681 & 372,9 & 89288 & 18158 & 77362 & 84538 & 74616 \\
\hline 5,87 & 14,214 & 446,4 & 93966 & 21306 & 80516 & 90404 & 80491 \\
\hline 6,41 & 29,274 & 439 & 98925 & 28881 & 82620 & 98437 & 89283 \\
\hline
\end{tabular}

Table 5

Dicraeosaurus hansemanni: estimates of relative segment masses $(\mathrm{m})(100 \%=$ head + neck), cross-sectional areas (A) of the intervertebral joints, and calculated compressive force $(\mathrm{k} \cdot \mathrm{F})$ on the intervertebral discs (see text for calculation method) at different locations along the neck $(A-D)$ for the hypothetical neck postures illustrated in Fig. 10. $x$ : distance from the occipital condyle. e: constant factor.

\begin{tabular}{|c|c|c|c|c|c|c|}
\hline $\mathrm{x}[\mathrm{m}]$ & $\mathrm{m}[\%]$ & $\mathrm{A}\left[\mathrm{m}^{-4}\right]$ & $\mathrm{e} \cdot \mathrm{F}_{\mathrm{A}}[\mathrm{N}]$ & $\mathrm{e} \cdot \mathrm{F}_{\mathrm{B}}[\mathrm{N}]$ & $\mathrm{e} \cdot \mathrm{F}_{\mathrm{C}}[\mathrm{N}]$ & $\mathrm{e} \cdot \mathrm{F}_{\mathrm{D}}[\mathrm{N}]$ \\
\hline 0,00 (head) & 22,003 & & & & & \\
\hline 0,21 & 2,135 & 28,51 & 1913 & 2218 & 127 & 1992 \\
\hline 0,38 & 4,433 & 44,05 & 2272 & 3109 & 492 & 2844 \\
\hline 0,59 & 6,076 & 54,52 & 2652 & 3015 & 870 & 3328 \\
\hline 0,82 & 6,732 & 78,76 & 3354 & 3121 & 1418 & 3987 \\
\hline 1,05 & 7,225 & 96,76 & 4482 & 3395 & 2259 & 5007 \\
\hline 1,32 & 9,688 & 99,40 & 6078 & 3766 & 3456 & 6312 \\
\hline 1,57 & 9,852 & 137,65 & 7866 & 4058 & 4816 & 7645 \\
\hline 1,84 & 10,509 & 127,55 & 8857 & 4460 & 5560 & 8192 \\
\hline 2,10 & 10,509 & 161,32 & 10184 & 4657 & 7376 & 8851 \\
\hline 2,30 & 10,837 & 152,60 & 10874 & 4979 & 9096 & 9241 \\
\hline
\end{tabular}

ous postures are also frequently utilised. In giraffes, stress patterns along the neck show little variation for the three non-vertical postures tested. However, the sensitivity of the Preuschoft method is well illustrated by the observation that even when a wide range of neck postures is utilised, the shape of the cervical vertebral column fits best to the predominant neck posture and not to the most strenuous posture that is occasionally adopted. An upright neck posture 


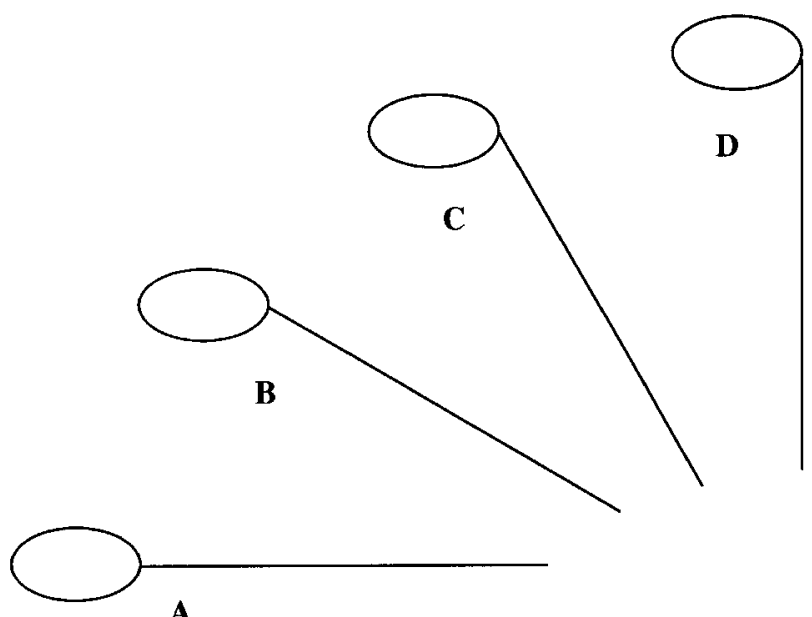

$\mathbf{A}$

Fig. 3. Hypothetical neck postures in the giraffe. A, horizontal; $\mathbf{B}, 60^{\circ}$ to the vertical; $\mathbf{C}, 30^{\circ}$ to the vertical; $\mathbf{D}$, vertical posture.

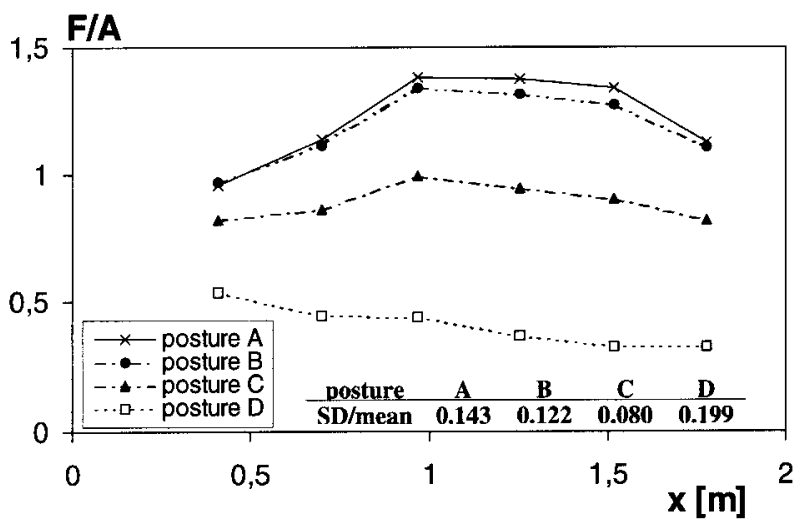

Fig. 4. Stress (F/A) on the intervertebral joints along the neck of a giraffe calculated for the hypothetical neck postures presented in Fig. 3. Stress is given in arbitrary units. $x$ : distance from the occipital condyle. $\mathrm{SD} /$ mean: standard deviation of stress values divided by mean stress.

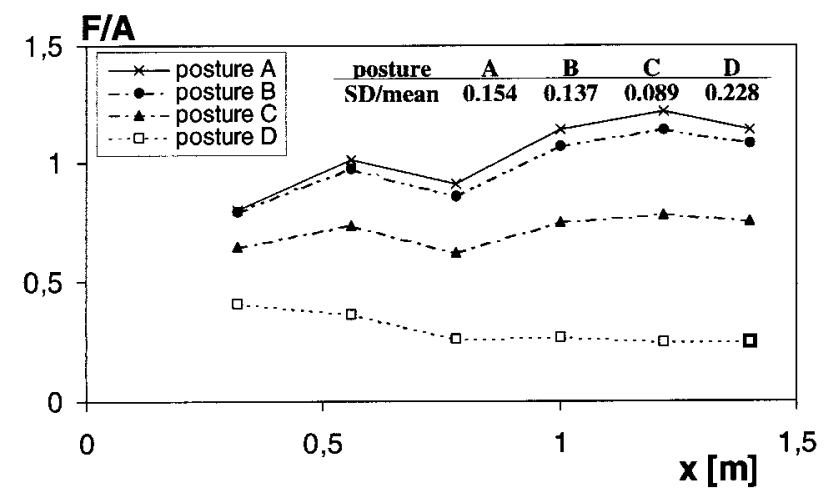

Fig. 5. Stress (F/A) on the intervertebral joints along the necks of a second giraffe. Explanation: see Fig. 4. SD/mean: standard deviation of stress values divided by mean stress.

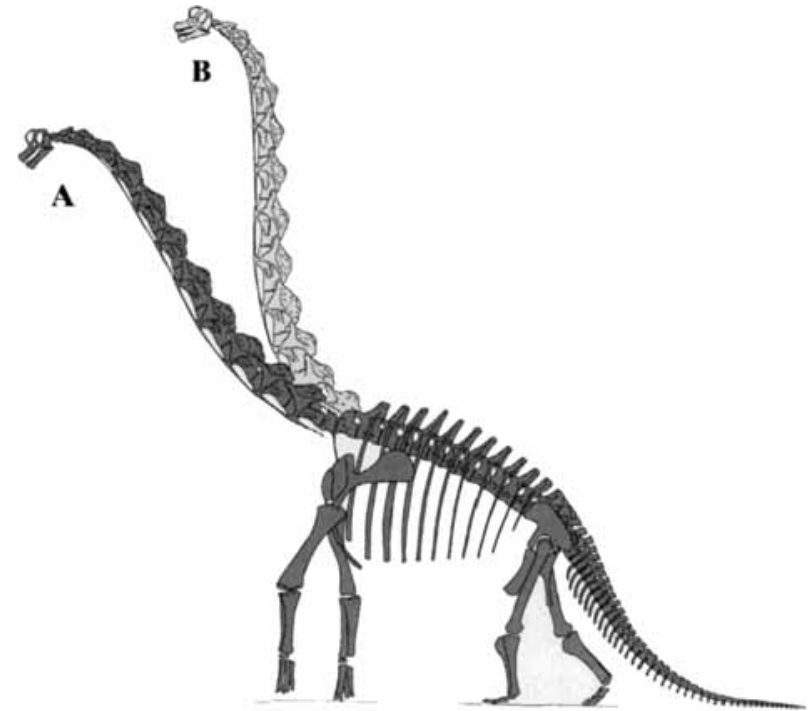

Fig. 6. Hypothetical neck postures for Brachiosaurus brancai. A, after Janensch (1950b); B, "vertical" posture. In addition, a fully horizontal posture was also tested.

(Fig. 3D) evokes the lowest stresses on the intervertebral discs. Giraffes, however, do not keep the neck in an upright posture frequently or over long time intervals. As expected, the variation of stress values along the neck is comparatively high in a vertical posture (SD/ mean $=0.199$ and 0.228 in the two individuals studied, respectively).

For Brachiosaurus brancai, the results are very clear (Figs 6, 7). In an upright neck posture, the stress is nearly constant along the first two thirds of the neck $(\mathrm{SD} /$ mean $=0.108)$. The steep increase of stress at the base of the neck could be explained by errors in the estimated lengths of lever arms. In this region of the neck, the lever

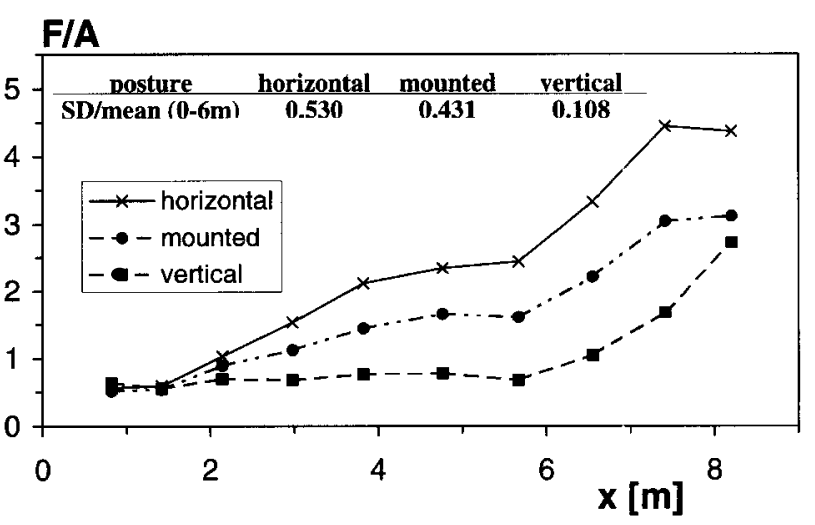

Fig. 7. Stress (F/A) on the intervertebral joints along the neck of Brachiosaurus brancai calculated for the hypothetical neck postures presented in Fig. 6 and for a horizontal neck posture. Stress is given in arbitrary units. $x$ : distance from the occipital condyle. SD/mean: standard deviation of stress values divided by mean stress in the anterior 6 meter of the neck. 


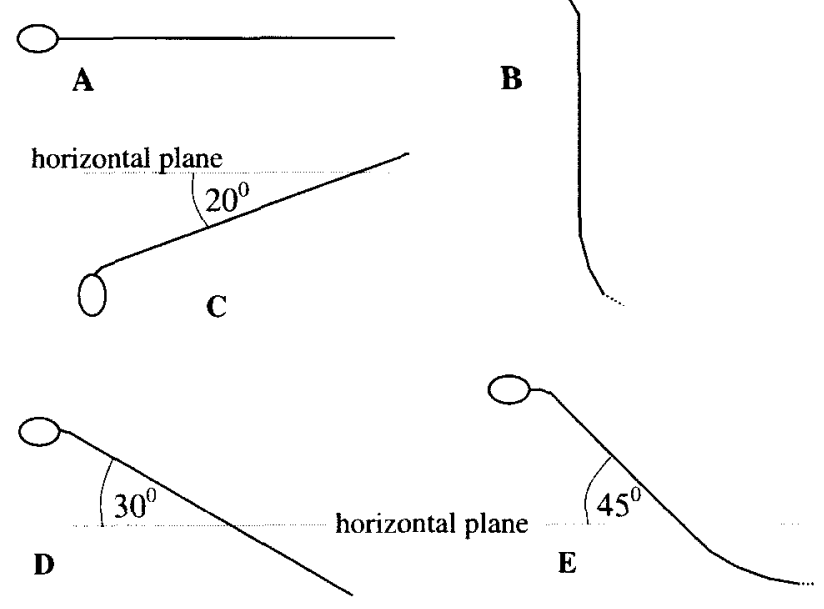

Fig. 8. Hypothetical neck postures for Diplodocus carnegii. A, horizontal; B, "vertical"; C, sloping down; D, moderately elevated; $\mathbf{E}$, elevated posture.

arms of epaxial muscles, tendons or ligaments may have been longer than assumed here, as discussed by Christian \& Heinrich (1998). Another explanation concerns potential bias in the data for segment mass. Weight forces acting on the intervertebral joints at the base of the neck may be overestimated because the mass of the distal neck segments possibly had been overestimated by Gunga et al. (1995, 1999), as mentioned above. Additionally, in a vertical posture, soft tissues of the basal neck region might have partly rested directly on the trunk, instead of having loaded the neck. However, even in a moderately inclined neck posture (the neck posture of the mounted skeleton in Berlin) and especially in a horizontal posture, the stress on the intervertebral discs in the first to thirds of the neck in-

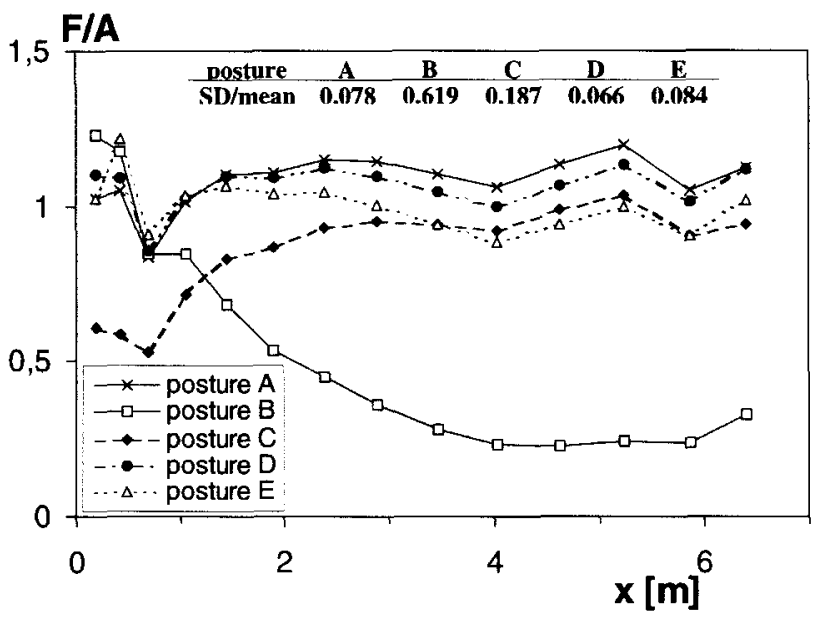

Fig. 9. Stress (F/A) on the intervertebral joints along the neck of Diplodocus carnegii calculated for the hypothetical neck postures presented in Fig. 8. Stress is given in arbitrary units. $x$ : distance from the occipital condyle. $\mathrm{SD}$ /mean: standard deviation of stress values divided by mean stress. creases by a factor of three or four, respectively, proving that neither of these postures was frequently adopted (SD/mean $=0.431$ and 0.530 , respectively, along the first two thirds of the neck).

By contrast, the steep decrease in stress along the neck of Dipolodocus (Figs 8,9) shows, that an upright posture of the neck (Fig. $8 \mathrm{~B}, \mathrm{SD} /$ mean $=0.619$ ) is not very likely the standard position in this sauropod. A horizontal (Fig. 8A) or a slightly elevated posture (Fig. 8D) yields the least variation in stress $(\mathrm{SD} /$ mean $=0.078$ and 0.066 , respectively). A gently sloping down position, as proposed by Stevens \& Parrish (1999), was not tested. Judged from the results presented here, such a posture was in the range of possible habitual postures in this sauropod. By contrast to Brachiosaurus, the data fit best to the most strenuous neck posture. Therefore, other postures that resulted in less stress in the intervertebral discs cannot be confidently excluded. However, the results strongly indicate that $D i$ plodocus frequently held its neck in a more or less horizontal posture. The striking differences between the results for Brachiosaurus and Diplodocus, are clearly consistent with proposals for different feeding strategies in these sauropods.

In Dicraeosaurus, the results are similar to those for Diplodocus (Figs 10, 11) but less conclusive. Whereas the hypotheses for a habitually upright or a sloping down neck posture are very unlikely $(\mathrm{SD} / \mathrm{mean}=0.396$ and 0.598 , respectively), neck posture could have been widely variable. A semi-upright posture (Fig. 10D) ap-

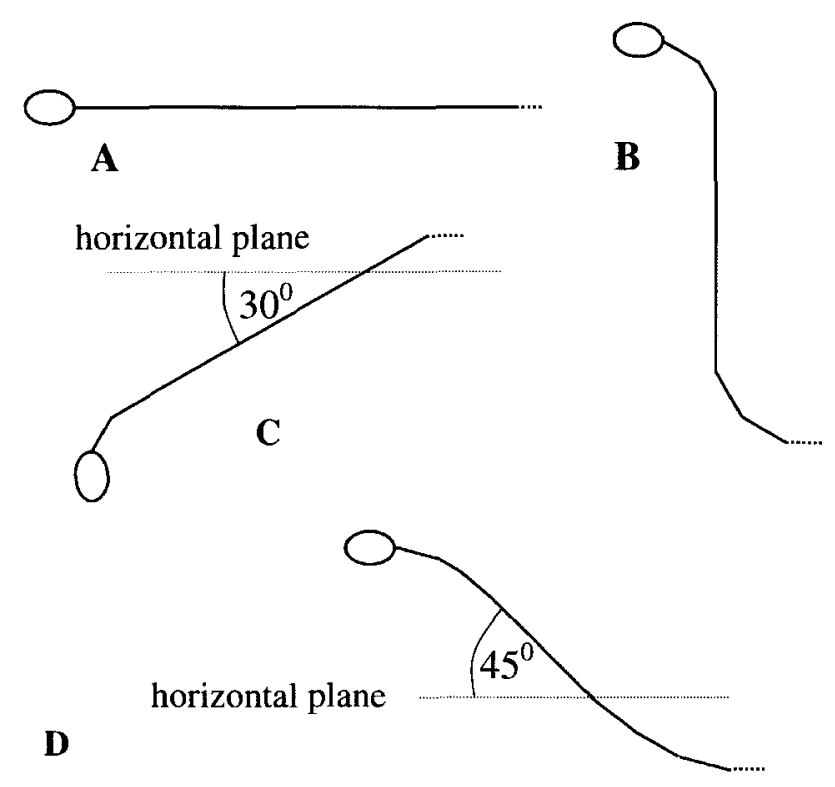

Fig. 10. Hypothetical neck postures for Dicraeosaurus hansemanni. A, horizontal; B, "vertical"; C, sloping down; D, elevated posture. 


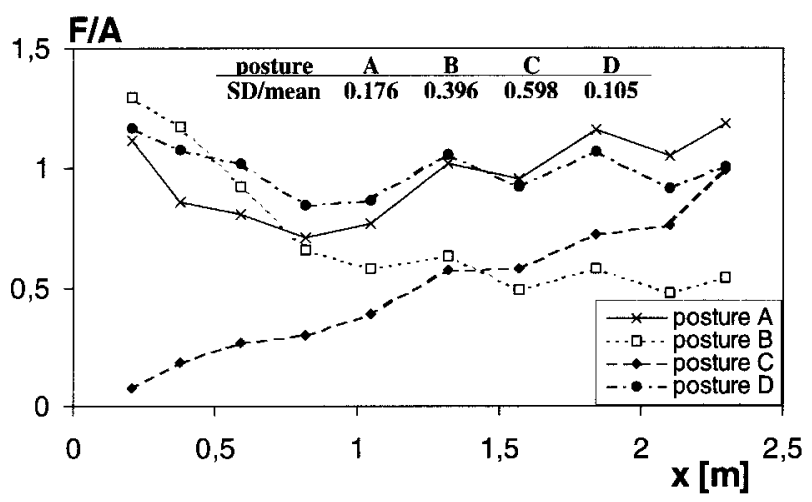

Fig. 11. Stress (F/A) on the intervertebral joints along the neck of Dicraeosaurus hansemanni calculated for the hypothetical neck postures presented in Fig. 10. Stress is given in arbitrary units. $\mathrm{x}$ : distance from the occipital condyle. SD/ mean: standard deviation of stress values divided by mean stress.

pears more likely $(\mathrm{SD} /$ mean $=0.105)$ than a horizontal posture (Fig. 10A, SD/mean $=0.176$ ). As in Diplodocus (and in giraffes), the neck may have been held occasionally and for short periods in a sloping down or an upright position.

In two of the sauropods, Diplodocus and $\mathrm{Di}$ craeosaurus, there appears to be a decline in stress between 0.5 and one meter caudal to the head for the most frequently assumed postures (Figs 9, 11). This reduction in stress might indicate that considerable forces other than forces that kept the neck in its position were of importance in this region. Such forces might have acted during feeding or during accelerations of the neck (Christian \& Preuschoft 1996). This reduction in stress observed in the neck region close behind the head is mainly due to comparatively long lever arms (h) in this neck region, indicating that the additional force acting in this region was not used for rapid accelerations of the head. Therefore, this force appears to have been effective during slow and strenuous activities like pulling slowly but forcefully at plants during feeding.

The stress values presented here cannot be compared across species because only relative values were calculated. Absolute values are not reliable because of difficulties in estimating the total neck mass and lever arms, as explained above.

\section{Discussion}

If applied to sauropods, the Preuschoft method corroborates the widespread view that species like Diplodocus carnegii and Dicraesaurus hanse- manni kept the neck at low or medium levels in order to sweep over a large feeding area (e.g., Dodson 1990). In the anterior region of the neck, at a distance of about 0.5 to one meter behind the head, additional forces appear to have been effective. Possibly, the neck was loaded in this region during feeding. A long tail was useful as counterweight, especially when the neck was moved sideways, so that high torques were transmitted to the trunk. Stout and short forelimbs were suitable for counteracting torques and sideways forces transmitted by the neck and tail to the trunk. The results obtained here are in fair agreement with the slightly sloping down neck posture of Diplodocus proposed by Stevens \& Parrish (1999). The results presented here, however, do not exclude the possibility that in the diplodocids studied upright neck postures were occasionally adopted (Bakker 1987, Paul 1988).

In Brachiosaurus brancai, stress patterns for the intervertebral discs along the neck are distinctively different from the patterns in Diplodocus carnegii and Dicraeosaurus hansemanni. These differences correspond with differences in body proportions (e.g., McIntosh 1990, Dodson 1990). The Preuschoft method, when applied to Brachiosaurus, clearly supports the idea of different feeding strategies among sauropods, proving that the neck of Brachiosaurus was held in a position much closer to the vertical than in the other species studied here.

As discussed by Christian \& Heinrich (1998), Brachiosaurus might have been able to hold the neck in a slightly inclined or even in a fully horizontal posture, although this is likely to have been infrequent and for short time intervals only. Because of the much higher compressive forces that acted along the neck in more horizontal postures, frequent utilisation of such positions should be reflected in much larger cross-sectional areas for the intervertebral discs, or in much longer lever arms for the epaxial muscles in the posterior two thirds of the neck.

The results for Brachiosaurus are in accordance with the reconstructions by Bakker (1987) and Paul (1988), but not with the idea that Brachiosaurus exploited a large feeding area without moving the trunk (e.g., Martin 1987). The long, but thin cervical ribs of Brachiosaurus are not suitable for sustaining high compressive forces, contrary to what was proposed by Frey \& Martin (1997), because inevitable deviations of an axial load would have resulted in the fracture of these bones. It seems more likely that the cervi- 
cal ribs have supported muscles, tendons, or ligaments that exerted tensile forces when the neck was flexed backwards (Christian \& Heinrich 1998) or during accelerations of the neck. Along a vertical neck, at least three different structures that resist tensile forces, one along the neural spines, and two along the cervical ribs, are necessary in order to stabilise the posture. However, the existence of cervical ribs does not prove a vertical neck posture. In a horizontal position of the neck, cervical ribs could have been useful in stabilising the neck during accelerations, as well.

With the neck held in an upright position, $\mathrm{Bra}$ chiosaurus did not need a very long tail as a counterweight, nor were the forelimbs necessarily very powerful in order to produce lateral forces. Instead, long forelimbs were useful for raising the position of the head, thereby increasing the maximum height for feeding. These deductions regarding the mechanical design of the forelimbs are supported by an analysis of limb bone dimensions in sauropods by Christiansen (1997) who showed, that the humerus of Brachiosaurus was much weaker in relation to its length than in many other sauropods including Diplodocus and Dicraeosaurus.

From an ecological point of view, different neck postures and therefore different feeding levels among sauropods appears reasonable. Yet, a habitually high position for the head makes it difficult to explain how a sufficiently high blood pressure could have been maintained (e.g., Badeer \& Hicks 1996, Seymour \& Lillywhite 2000). Nevertheless, the results presented here leave little doubt that Brachiosaurus was able to maintain the head in a high position above the ground for long periods. If this was possible only under certain physiological conditions, such as a low metabolic rate, the results presented here are of significance for debates concerning the physiology of sauropods.

\section{Acknowledgements}

I am very much obliged to the Museum für Naturkunde der Humboldt-Universität zu Berlin, especially Dr. W.-D. Heinrich, the Museum Alexander Koenig, Bonn, the Zoo Dortmund, and the Allwetterzoo Münster, all in Germany, for their friendly support in collecting data. Dr. H.-Chr. Gunga, and Dr. A. Wiedemann supplied original data for segment masses along the necks of sauropods analysed in this study. G. Christian assisted in collecting data. I thank Dr. D. Henderson, Prof. Dr. H. Preuschoft, Dr. M. Sander and Dr. D. Unwin for critical and constructive surveys of the manuscript.

\section{References}

Alexander, R. McN. 1985. Mechanics of posture and gait of some large dinosaurs. - Zoological Journal of the Linnean Society 83 (1): 1-25.

- 1989. Dynamics of dinosaurs and other extinct giants. 167 pp., Columbia University Press, New York.

Bakker, R. 1987. The dinosaur heresies. A revolutionary view of dinosaurs. 481 pp., Longman, Harlow.

Badeer, H. S. \& Hicks, J. W. 1996. Circulation to the head of Barosaurus revised: theoretical considerations. - Comparative Biochemistry \& Physiology A114: 197-203

Bonaparte, J. F. 1986. The early radiation and phylogenetic relationship of the Jurassic sauropod dinosaurs, based on vertebral anatomy. In Padian, K. (ed.). The Beginning of the Age of Dinosaurs: 247-258, Cambridge Univ. Press, Cambridge.

Christian, A. \& Heinrich, W.-D. 1998. The neck posture of Brachiosaurus brancai. - Mitteilungen des Museums für Naturkunde Berlin, Geowissenschaftliche Reihe 1: 73-80.

Christian, A. \& Preuschoft, H. 1996. Deducing the body posture of extinct large vertebrates from the shape of the vertebral column. - Palaeontology 39 (4): 801-812.

Christiansen, P. 1997. Locomotion in sauropod dinosaurs. Gaia 14: $45-75$.

Dagg, A. I. \& Foster, J. B. 1976. The giraffe: Its biology, behavior, and ecology. 210 pp., Van Nostrand Reinhold, New York.

Dodson, P. 1990. Sauropod Paleoecology. In Weishampel, D. B., Dodson, P. and Osmólska, H. (eds). The Dinosauria: 402-407. University of California Press, Berkeley, Los Angeles and London.

Fastovsky, D. E. \& Weishampel, D. B. 1996. The evolution and extinction of the dinosaurs. 460 pp., Cambridge University Press, Cambridge.

Frey, E. \& Martin, J. 1997. Long necks of Sauropods. In Currie, P. J. \& Padian, K. (eds). Encyclopedia of Dinosaurs: 406-409, Academic Press, San Diego etc.

Gunga, H.-C., Kirsch, K., Baartz, F., Röcker, L., Heinrich, W.-D., Lisowski, W., Wiedemann, A. \& Albertz, J. 1995. New data on the dimensions of Brachiosaurus brancai and their physiological implications. - Naturwissenschaften 82 (4): 189-192.

Gunga, H.-C., Kirsch, K., Rittweger, J., Röcker, L., Clarke, A., Albertz, J., Wiedemann, A. Mokry, S. , Suthau, T., Wehr, A., Heinrich, W.-D. \& Schultze, H.-P. 1999. Body size and body volume distribution in two sauropods from the Upper Jurassic of Tendaguru (Tanzania). - Mitteilungen des Museums für Naturkunde Berlin, Geowissenschaftliche Reihe 2: 91-102.

Gunga, H.-C. \& Kirsch, K. 2001. Von Hochleistungsherzen und wackeligen Hälsen. - Forschung 2-3: 4-9.

Hargens, A. R., Millard, R. W., Pettersson, K. \& Johansen, K. 1987. Gravitational haemodynamics and oedema prevention in the giraffe. - Nature 329: 59-60.

Hohnke, L. A. 1973. Haemodynamics in the Sauropoda. Nature 244: 309-310.

Kummer, B. 1959. Bauprinzipien des Säugerskeletes. 279 pp., Thieme, Stuttgart.

McIntosh, P. 1990. Sauropod Paleoecology. In Weishampel, D. B., Dodson, P. and Osmólska, H. (eds). The Dinosauria: 345-401. University of California Press, Berkeley, Los Angeles and London.

Janensch, W. 1950. Die Skelettrekonstruktion von Brachiosaurus brancai. - Palaeontographica, Supplement VII, 1. Reihe, Teil 3, Lieferung 2: 95-103.

Martin, J. 1987. Mobility and feeding of Cetiosaurus (Saurischia: Sauropoda) - why the long neck? In Curry, P. J. \& Koster, E. H. (eds). 4th Symp. Mesozoic Terrestrial Ecosystems. Short Paper: 154-159. Tyrell Museum of Paleontology, Drumheller, Alberta.

Paul, G. S. 1987. The science and art of restoring the life appearance of dinosaurs and their relatives. In Czerkas, 
S. J. \& Olsen, E. C. (eds). Dinosaurs Past and Present, vol. 2: 5-49. Natural History Museum of Los Angeles County, Los Angeles.

- 1988. The brachiosaur giants of the Morrison and Tendaguru with a description of a new subgenus, Giraffatitan, and a comparison of the word's largest dinosaurs. - Hunteria 2 (3): 1-14.

Pauwels, F. 1965. Gesammelte Abhandlungen zur funktionellen Anatomie des Bewegungsapparates 543 pp., Springer Verlag, Berlin, Göttingen, Heidelberg.

Pedley, T. J. 1987. How giraffes prevent oedema. - Nature 329: $13-14$.

Preuschoft, H. 1969. Statische Untersuchungen am Fuß der Primaten. I. Phalangen und Metatarsalia. - Zeitschrift für Anatomie und Entwicklungs-Geschichte 129: $285-345$.

- 1970. Statische Untersuchungen am Fuß der Primaten. II. Statik des gesamten Fußes. - Zeitschrift für Anatomie und Entwicklungs-Geschichte 131: 156-192.
- 1976. Funktionelle Anpassung evoluierender Systeme. Aufsätze und Reden der Senckenbergischen Naturforschenden Gesellschaft 28: 98-117.

Preuschoft, H. \& Fritz, M. 1977. Mechanische Beanspruchung im Bewegungsapparat von Springpferden. - Fortschritte der Zoologie 24: 75-98.

Preuschoft, H. \& Günther, M. M. 1994. Biomechanics and body shape in primates compared with horses. - Zeitschrift für Morphologie und Anthropologie 80 (1): $149-165$.

Seymour, R. S. 1976. Dinosaurs, endothermy and blood pressure. - Nature 262: 207-208.

Seymour, R. S. \& Lillywhite, H. B. 2000 . Hearts, neck posture, and metabolic intensity of sauropod dinosaurs. Proceedings of the Royal Society of London 267 (B): 1883-1887.

Stevens, K. A. \& Parrish, M. J. 1999. Neck posture and feeding habits of two Jurassic sauropod dinosaurs. - Science 284: 798-800. 